\title{
RELIABILITY BASED MAINTENANCE METHODOLOGY FOR SUSTAINABLE TRANSPORT ASSET MANAGEMENT
}

\author{
${ }^{1}$ Ejiroghene Onome EKPIWHRE, ${ }^{2}$ Kong Fah TEE \\ Department of Engineering Science, University of Greenwich, Kent, ME4 4TB \\ United Kingdom, e-mail: ${ }^{1}$ e.ekpiwhre@gre.ac.uk, ${ }^{2}$ K.F.Tee@gre.ac.uk
}

Received 13 February 2017; accepted 4 September 2017

\begin{abstract}
Functional failures and structural deterioration defects are among the leading causes of growing failure probabilities of the road systems and networks. Thus, asset maintenance intervention is an essential task for the unified management of road assets and systems. The objective of this research is to consider reliability based probabilistic approach established on functional failure mode, effects and criticality analysis parametric reliability analysis, risk-based assessment and strategic asset deterioration decisions. The combined progressive assessment frameworks and algorithms based procedures utilize service inspection, safety inspection and survey inputs. The illustrated reliability maintenance based methodologies offer sustainable asset management for highway transport infrastructure and systems with emphasis on resolutions to their functional failures, defect related risk and appropriate deterioration treatment.
\end{abstract}

Keywords: Highway assets, Reliability centered maintenance, Reliability growth curves, Risk based inspection, Deterioration treatment decisions

\section{Introduction}

The highway infrastructures are vital for any nation's economic wellbeing and are often the most valuable asset for local authorities but still do not often receive the anticipated attention that commensurates an optimal state of its operations and maintenance [1]. The code of practice for the maintenance of highway structures [2] portrays some key importance of a well maintained and available highway infrastructure, which brings better economic, social and environmental wellbeing of any country. The arrangement for the management of highway maintenance is best effective when set within the framework of an overall asset management regime. The 
catastrophic effect and consequences of the lack of reliable based asset management solutions often lead to reduced system safety, decreased asset availability, short asset lifetime resulting in an increased whole life cycle cost [3] or total renewal. Fig. 1 shows the failed (a) and the renewed (b) condition of a road junction network.

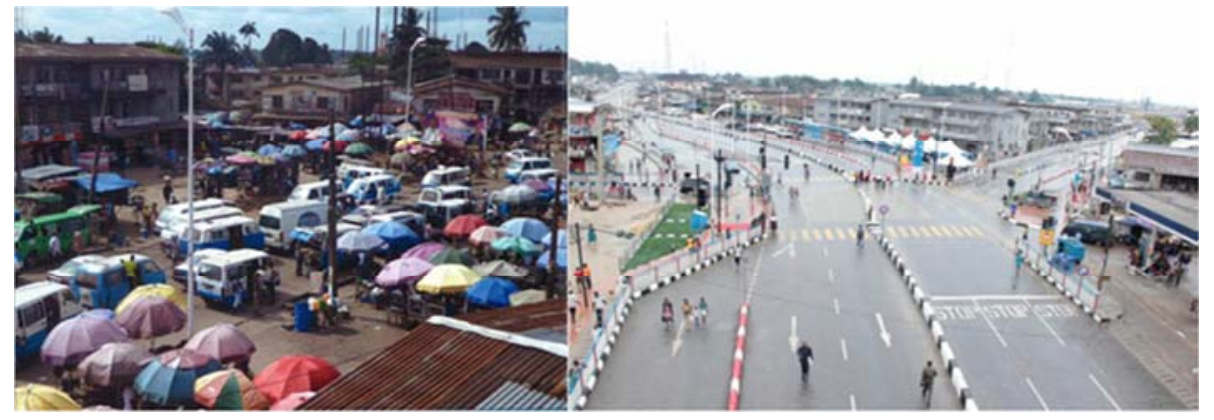

a)

b)

Fig. 1. Drone view of a road junction network, a) failed and b) renewed state

Frameworks provide the means of understanding the value and liability of the asset, giving authorities and asset owners a better understanding of the asset condition in taking a right strategic decision [4]. The choices of highway asset conception, operation, inspection, maintenance, renewal and disposal require an asset management framework to achieve a safe and cost-effective infrastructure system. The likelihood of major appalling asset failures and budget challenges can be decreased by the application of asset management tools. Highway assets and elements are multifaceted physical assets that consist of different road infrastructure (e.g. pavement, safety systems, traffic system, lighting systems, road surface systems). The road authority does not own some others highway elements that make up the road network (e.g. post office box, utility services). In consideration of the complexity of the various disparate highway assets, a mere technique is not feasible to carry out an effective maintenance. Instead, a more strategic procedure is required with consideration of various highway asset types, their diverse, unique functions, intermittent functional failures and random deterioration pattern.

The advancement in computer technology has aided understanding prognosis associated with ageing of many critical structures (e.g. buildings, bridges, highway infrastructures, underground pipelines, offshore structures, mechanical structures). However, the need for renewed reliable methods and models are still required in highway asset functional Failure Mode, Effects and Criticality Analysis (FMECA), parametric reliability analysis, risk-based inspection and assessment, strategic deterioration models, and treatment cost optimisation. The contents of this paper are organized as follows. In Section 2, reliability based maintenance process is projected. 2.1, Reliability Centered Maintenance (RCM) strategy is presented. Reliability analysis and growth curves modeling are discussed in Section 2.2. In Section 2.3, a risk based inspection and assessment of category 2 defects are discussed, and in conclusion of the 
models, section 2.4, deliberated on the strategic treatment of deterioration prediction. Finally, an application applied to carriageway is used to validate the proposed models in Section 3 and the conclusion and discussion are presented in Section 3.

\section{Reliability based maintenance process}

Amongst the drive of a reliability based maintenance practice for a sustainable transport asset management is the developmental support highway infrastructure brings providing the base for essential services a vibrant economy requires. However, managing highway infrastructures that are reliable, safe to user and cost effective to infrastructure owners is a challenging task. The functional failure and gradual deterioration of road assets are very precarious to an economy surface transportation with its effect diffusing throughout its entire networks. The results of highway assets in their poor condition with continuous functional failures lead to increased operating cost, longer travel time and damage to the vehicle to road users [5]. The unavailability of highway assets not only account for high accident rates but also are considered originators of most traffic congestion and accidents [6]. The highway assets of the road network often handle more traffic than they are often designed for, therefore requiring an adequate road traffic management systems. This section defines the approaches proposed to achieve a reliable based maintenance asset management with consideration of highway infrastructure.

Maintenance, which is a core function for sustaining long-term profitability of assets by organizations, is defined as a combination of all actions with intent to restore the asset to its original state or a state where it can perform its required function. This report devices a novel approach using systematic knowledge of the basics of reliability [7], [8], [9], risk [10], [11], deterioration [12], [13] and cost strategies [3], [14] and models embedded in qualitative and quantitative assessment methods as it is shown in Fig. 2 recognizing that algorithms support effective optimizations of systems [15], [16].

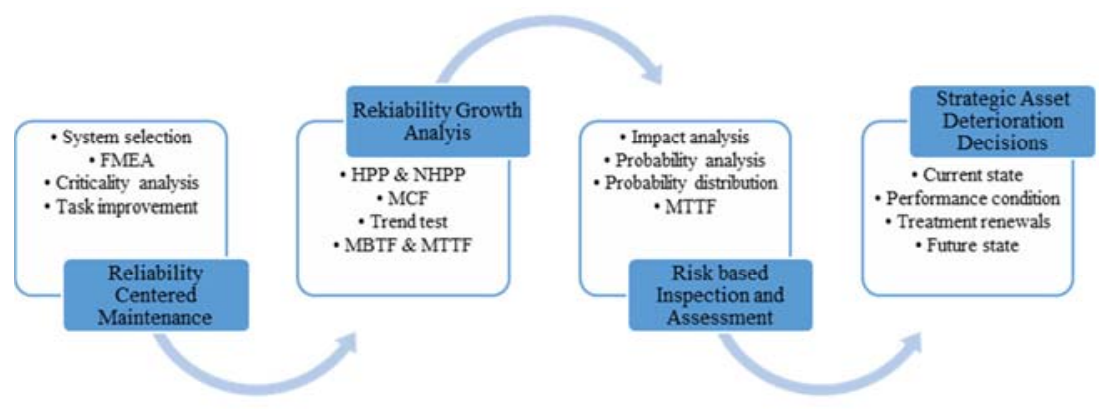

Fig. 2. Reliability-based maintenance methods for asset sustainability

\subsection{Reliability, centered maintenance}

The Reliability Centered Maintenance (RCM) is a technique that determines the maintenance requirement of a system and the interims at which these are to be carried 
out in its operating context through a failure mode, effects and criticality analysis. It focuses on the functions and failures of the assets as well as identifies their consequences. It uses a standardized logical resolution procedure to implement preventive measures from these identified consequences. RCM techniques decide the required maintenance of a system while in its operating environment. The asset management institute classifies RCM as a control that supports optimized management of physical assets. RCM combines different approaches to aid the development of a systematic maintenance program to manage risks as a basis for maintenance decisions [17]. RCM framework focuses on preserving system functions, rather than preserving physical asset since it offers asset availability, reliability and maintainability. RCM process ensures seven key questions are answered reasonably order as follows:

I. What are the functions and associated desired standards of performance of the asset in its present service context (functions)?

II. In what ways can it fail to accomplish its functions (functional failures)?

III. What causes each functional failure (failure modes)?

IV. What transpires when each failure occurs (failure effects)?

V. In what way does each failure matter (failure consequences)?

VI. What should be done to forecast or prevent each functional failure (proactive tasks and task intervals)?

VII. What should be done if an appropriate proactive task cannot be found (default actions)?

The RCM process as conveyed below provides the most information and details about asset functions, failure modes, criticality analysis and maintenance actions that address the functional failures. The process analysis is explained as follows and further reading in [18] and its developed case study application capturing highway assets [7].

System partitioning: This identifies all the technical information of functionally significant items. The asset descriptive and operational information (e.g. asset defect, defect categories, defect period, repair hours, repair cost) are gathered from traditional expert judgment, maintenance literature and computerized maintenance management systems as related to the individual asset.

Failure Mode Effect Analysis (FMEA): The principal causes of functional failure are identified in this step. The functional failure is an unsatisfactory condition, which results from an asset not adequately providing its intended function. It captures assets functions, functional failure, failure modes and failure effects. The specific situation causing the functional failure is known as a failure mode, while the arising consequences are called failure effects. This step is the most critical phase in the RCM analysis as it provides the basic information for decision logic analysis as well as the quality of the proposed preventive maintenance programme.

RCM decision logic and criticality analysis: It uses decision rationality of Yes and No questions to find an optimal balance between the best maintenance tasks since making a final judgment from old-style expert judgments in highway asset maintenance is difficult. Maintenance tasks are chosen based on 8 decision logic questions as shown in Table I and Table II with consideration of the criticality classes. 
In consideration of the most appropriate and effective task, the Question 1-3 in Table I is used in developing Table II bestowing the criticality analysis using (Y Yes, $\mathrm{N} \sim \mathrm{No}$ and N/A Not applicable). The effectiveness in Question 4-7 is utilized in producing the criticality class (A Safety \& environment, B Mission, C $\sim$ All others failures and D Hidden Failure).

Table I

RCM decision logic

\begin{tabular}{|c|c|c|c|c|}
\hline \multicolumn{5}{|c|}{ RCM DECISION LOGIC TABLE } \\
\hline Q & \multicolumn{2}{|r|}{ Logic } & \multicolumn{2}{|l|}{ Decision } \\
\hline 1 & \multicolumn{2}{|c|}{$\begin{array}{l}\text { Is the incidence of a failure } \\
\text { evident to the working crew while } \\
\text { it is performing its normal duties? }\end{array}$} & $\begin{array}{l}\text { Yes }=\text { Go to Question } 2 \\
\text { No }=\text { Go to Question } 7\end{array}$ & $\begin{array}{l}\text { Evident Failure } \\
\text { Hidden Failure }\end{array}$ \\
\hline 2 & \multicolumn{2}{|c|}{$\begin{array}{l}\text { Does failure cause loss of function } \\
\text { damage that has a direct and } \\
\text { adverse effect on operating } \\
\text { safety? }\end{array}$} & $\begin{array}{l}\text { Yes }=\text { Go to Question } 4 \\
\text { No }=\text { Go to Question } 3 \\
\text { Capability }\end{array}$ & $\begin{array}{l}\text { afety Capability } \\
\text { Operational }\end{array}$ \\
\hline 3 & \multicolumn{2}{|c|}{$\begin{array}{l}\text { Does failure have a direct and } \\
\text { effect on operational capability? }\end{array}$} & $\begin{array}{l}\text { Yes }=\text { Go to Question } 5 \\
\text { Capability } \\
\text { No = Go to Question } 6\end{array}$ & $\begin{array}{l}\text { Operational } \\
\text { All Others }\end{array}$ \\
\hline \multirow[t]{3}{*}{$\begin{array}{l}4- \\
7\end{array}$} & \multicolumn{4}{|c|}{$\begin{array}{l}\text { Is there an effective and applicable preventive maintenance task or a combination of } \\
\text { tasks that can prevent functional failures? }\end{array}$} \\
\hline & \multicolumn{2}{|c|}{ Effectiveness } & \multicolumn{2}{|l|}{ Rules } \\
\hline & $\begin{array}{l}\text { Q4 } \\
\text { Q5 } \\
\text { Q6 } \\
\text { Q7 }\end{array}$ & $\begin{array}{l}\text { Safety and Environment } \\
\text { Mission } \\
\text { All Others } \\
\text { Hidden Failure }\end{array}$ & $\begin{array}{l}\text { Probability of failure redu } \\
\text { Risk of failure reduced to } \\
\text { Cost of maintenance is less } \\
\text { Consequences of hid } \\
\text { Yes =Describe/Classify; }\end{array}$ & $\begin{array}{l}\text { d to very low } \\
\text { ceptable level } \\
\text { an cost of repair } \\
\text { en failure } \\
o=\text { Go to } Q 8\end{array}$ \\
\hline 8 & & $\begin{array}{l}\text { eduled failure finding task } \\
\text { and justified? }\end{array}$ & No $=$ Con & $\begin{array}{l}\text { es }=\text { Specify task } \\
\text { der safety design }\end{array}$ \\
\hline
\end{tabular}

Table II

Criticality analysis and class

\begin{tabular}{|c|c|c|l|}
\hline \multicolumn{3}{|c|}{ CRITICALITY ANALYSIS } & \multirow{2}{*}{ CRITICALITY CLASS } \\
\hline Q1 & Q2 & Q3 & \\
\hline Y & $\mathrm{Y}$ & N/A & A=Safety/Environments \\
Y & $\mathrm{N}$ & $\mathrm{Y}$ & $\mathrm{B}=$ Mission \\
$\mathrm{Y}$ & $\mathrm{N}$ & $\mathrm{N}$ & $\mathrm{C}=$ All Other Function \\
$\mathrm{N}$ & $\mathrm{N} / \mathrm{A}$ & $\mathrm{N} / \mathrm{A}$ & $\mathrm{D}=$ Hidden Failure \\
\hline
\end{tabular}

Maintenance task improvement: The maintenance task improvement comprises developing Preventive Maintenance (PM) tasks and combining effective PM policy. Evaluating existing maintenance classifications and intervals are useful in developing PM programme for assets. 


\subsection{Reliability analysis and growth curves modeling}

The instantaneous and cumulative effect of failure rate for repairable fielded systems on the road network depletes the reliability of road network systems. A repairable system is a system, which after failing to perform one or more of its functions satisfactory can be restored to entirely satisfactory performance [19]. The restoration can be by ways and means other than replacement of the whole system. Repairable systems are classified into three categories namely minimal repair, normal repair and perfect repair based on the outcome on its repair level. The most common used models for the failure process of repairable systems are:

I. Renewal Process (RP) or Homogeneous Poisson Process (HPP) model perfect/maximal repair;

II. Generalized renewal process (correction and rejuvenation) normal/partial repair; and

III. Non-Homogeneous Poisson Process (NHPP) model imperfect/minimal repair.

The organization chart in Fig. 3 portrays the fundamental relationship between established classes of models and their dependence to failure intensities.

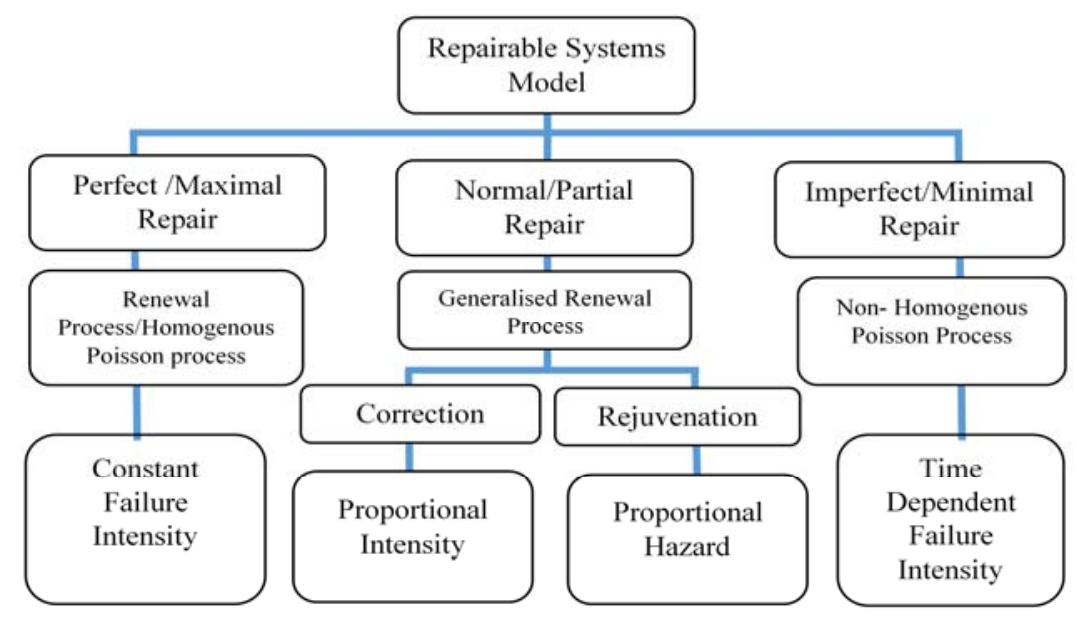

Fig. 3. Failure intensity relationship between models of repairable systems

In this critique, reliability growth for the improvement of repairable road pavement systems is anticipated. Reliability behavior of highway asset is assessable using reliability estimates of it Mean Time To Failure (MTTF) for instantaneous failure time of the event and Mean Time Between Failure (MTBF) for cumulative times of events. Although RCM achieved the maintenance interventions predictions for highway assets via FMECA, quantitative judgments on the MTTF and MTBF were not captured as RCM is more of a qualitative approach. In the representations of reliability growth analysis by Crow and Duane are the most frequent amongst the foremost in proposing the idea that improvements times can be represented mathematically. The prominent 
relationship between both Duane and Crow-AMSAA model is their observed cumulative MTBF and cumulative test logarithm time having a linear association [20], [21]. This extension ability of the CROW-AMSAA methodology has allowed for estimations in failure intensity and cumulative failures.

The growth trend and parametric growth curves of HPP and NHPP power law are presented using Maximum Likelihood Estimation (MLE) and Least Square Estimation (LSE) as well as their computed Mean Cumulative Function (MCF) of failure times of events as expounded below.

Homogeneous Poisson Process (HPP): The Poisson process of the HPP has a constant intensity function. The Poisson process is perceived not suitable for systems that are either improving or deteriorating. Thus the model is only appropriate when the intervals between failures do not systematically increase or decrease.

Non-Homogeneous Poisson Process (NHPP): The process can either be a power law process or exponential law process. The intensity function of the systems represents the rate of failures or repairs. Thus, the system reflects an improvement over the operational time. When simulating a validation to track improvement, deterioration or stability of the system, the NHPP power law process is classified as an AMSAA model if MLE method is used and a Duane model if LSE method is utilized.

Mean Cumulative Function (MCF): The MCF portrays the average cumulative number of failures or cost of the overall system in the investigated time interval. Conceding that the resultant output of the MCF produced by the NHPP indicates an increased, constant or decreased rate of system failure, the HPP has a constant failure rate resulting in a straight line.

Trend test: Testing of trends in inter-failure times is a key aspect of the analysis of failure time of event data for the repairable system. Event plots and Total Test of Time (TTT) are possible to define the trends of inter failure times. The right censored datasets are computable with any of the three most prolific trend tests namely; MIL-Hdbk-189 (the military handbook test), Laplace and Anderson-Darling.

\subsection{Risk-based inspection and assessment}

The importance of inspection and maintenance for system and assets of civil engineering infrastructures is of high priority. The consequences could be fatal and severe if poorly maintained and the most importantly, depreciation, which can be very costly. The connection of quantitative risk analysis to maintenance has not been effusively studied. Also, there is an absence of systemic, risk-based maintenance methodologies that can solve the problems facing highway agency maintenance programme. These inspections are anticipated to identify defects with the potential to cause harm, danger or serious inconvenience to road users of the network and the community environs. An onsite inspection is conducted to identify and assess the risk of the defect, and after that based on the extent, defects are categorized into Category 1 [CAT.1] and Category 2 [CAT.2] with appropriate response time. The risk associated with the hazards or dangers on the site are identified, and risk-based analysis is often 
developed to address the findings of the safety inspections [22]. CAT.1 defects are those defects requiring urgent attention since they signify an immediate or imminent hazard or because there is a risk of structural deterioration within a short period. CAT.2 defects consist of all other defects deemed not to represent an immediate hazard as CAT.1 and are further categorized based on priority namely High (H), Medium (M) and Low (L).

Techniques used in risk assessment and analysis in literature are numerous, unique and suitable for different applications. The most common risk analysis are in two categories namely deterministic (quantitative \& qualitative) and stochastic (statistics \& forecasting), [23], [24]. The stochastic approach used is presented in Table III.

Table III

Stochastic techniques

\begin{tabular}{|c|c|}
\hline Categories & Analysis Techniques \\
\hline $\begin{array}{l}\text { Classic } \quad \text { Statistics } \\
\text { Approach (CSA) }\end{array}$ & $\begin{array}{l}\text { Probability Distribution - Exponential, Normal, Lognormal, } \\
\text { Weibull } \\
\text { Event data models -MTTF/Mean Time to Repair (MTTR) Model, } \\
\text { Time at Risk Failure Model, Poisson Model }\end{array}$ \\
\hline $\begin{array}{l}\text { Accident } \\
\text { Forecasting } \\
\text { Modelling (AFM) }\end{array}$ & $\begin{array}{l}\text { Time-Series, Markov Chain Analysis, Grey Model, Scenario } \\
\text { Analysis, Regression Method, Neural Networks }\end{array}$ \\
\hline
\end{tabular}

The risk assessment framework based on Risk Based Inspection (RBI) intertwined a Dual Stochastic (MTTR-PDF) approach. The algorithm in Fig. 4 evaluates the RBI assessment to enable a stochastic application to pilot its outcomes. The approach overcomes the precincts of inherent risk practices for defects on highway assets offering a systematic and coherent way to manage the assets [22] as it is applied in case study [10].

The consequence/impact analysis: The captured impact of the defected asset is estimated as the scale of the defect to the asset and on the social-economic significance of the asset status. The defect size and the impending level are used to factor a score.

The likelihood/probability analysis: This is used for scoring the defect after inspection. The severity of the defect and the potential failure that could arise from the defect as well as the assumed rate of deterioration is phantom.

Defect category analysis: The resultant scores from the consequence/impact and likelihood/probability analysis in union with the risk register for consistency are used to classify the defect as CAT.1 or CAT.2 defect to aid maintenance response prioritization.

Repair response analysis: The repair response is divided into response time scale based on the risk level (e.g. 1 to 9,1 to 25). A risk level at 1 indicates low priority and is classified as the lowest impact while 9 or 25 as high requiring fastest response time.

Stochastic classical statistical approach: The combined stochastic process Mean Time to Repair (MTTR)-Probability Distribution Function (PDF) accurately estimates the maintenance interval outcome of the defected period. The mean $(\mu)$ and standard deviation $(\sigma)$ generated from MTTR interval from the sampled safety inspection data set 
is sampled to derive the best fit PDF trend of each defect category. The best fit PDF is generated using the most precise interval $\mu$ and $\sigma$, predicting the most current MTTR interval for the various defect categories [10].

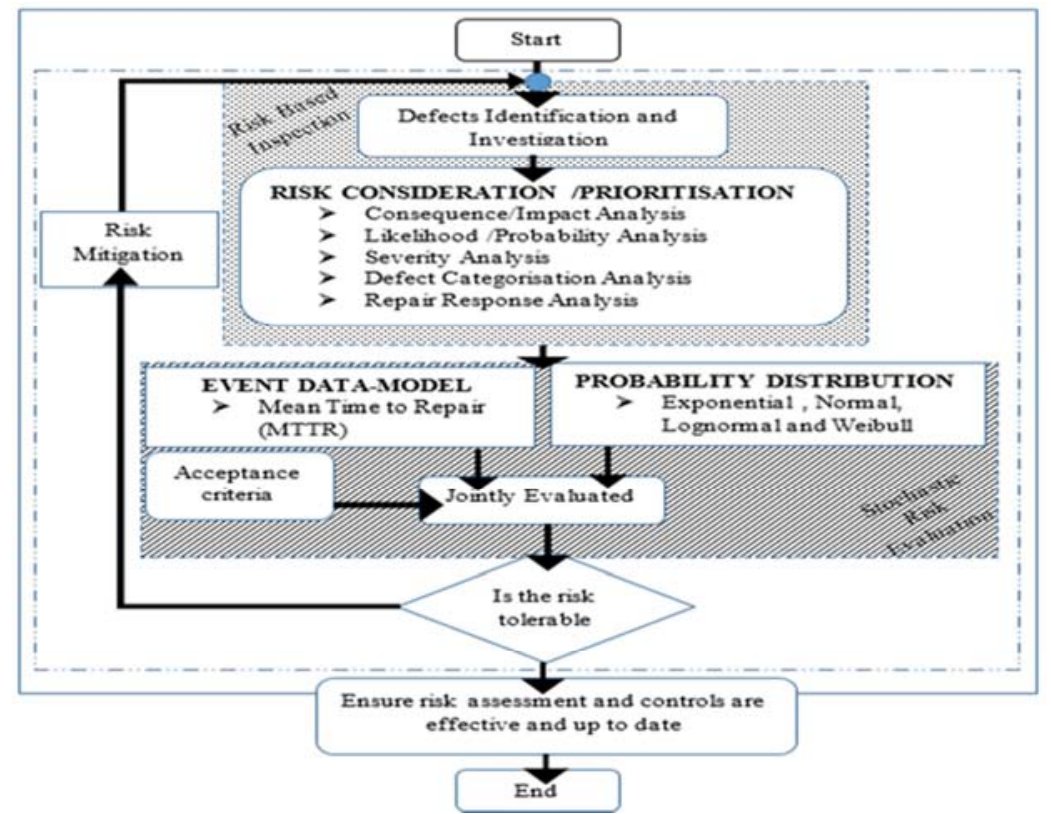

Fig. 4. Flowchart of RBI-Stochastic assessment framework

\subsection{Strategic management of asset deterioration decision}

The accurate predictions of the Current State (CS) and Forthcoming State (FS) of highway infrastructures are crucial for developing appropriate inspection and maintenance regimes for newly created or existing highway infrastructures. The likelihood of optimal performance is the function of the CS (before treatment), the treatment type and treatment cost in obtaining its FS (after treatment). The condition of the CS of these repairable assets is the base unit for forecasting and implementing their desired maintenance [12], [25], [26]. These attributes have gained importance because asset owners and managers are interested in knowing the relationship between the CS of their asset and the output of the maintenance process. A strategic ideal for asset deterioration decision is modelled in Fig. 5. The definition of the attributes of the strategic model is described in Table IV for ease of reference.

The application case procedure [14] as it is shown in the strategic model in Fig. 5, displays the trail of the strategic cost model to enable assets owners to determine the best time to carry out treatment for their assets. The performance condition requires variables from the current state of the asset and the utilized performance transition in computing its future state. In the case of the treatment renewal of the current condition bands, the treatment cost of the repair level is required. The asset performance condition 
is classified using condition band (e.g. 1-Very Good, 2-Good, 3-Fair, 4-Poor and, 5Very Poor) as the starting point CS for subsequent planning for the network.

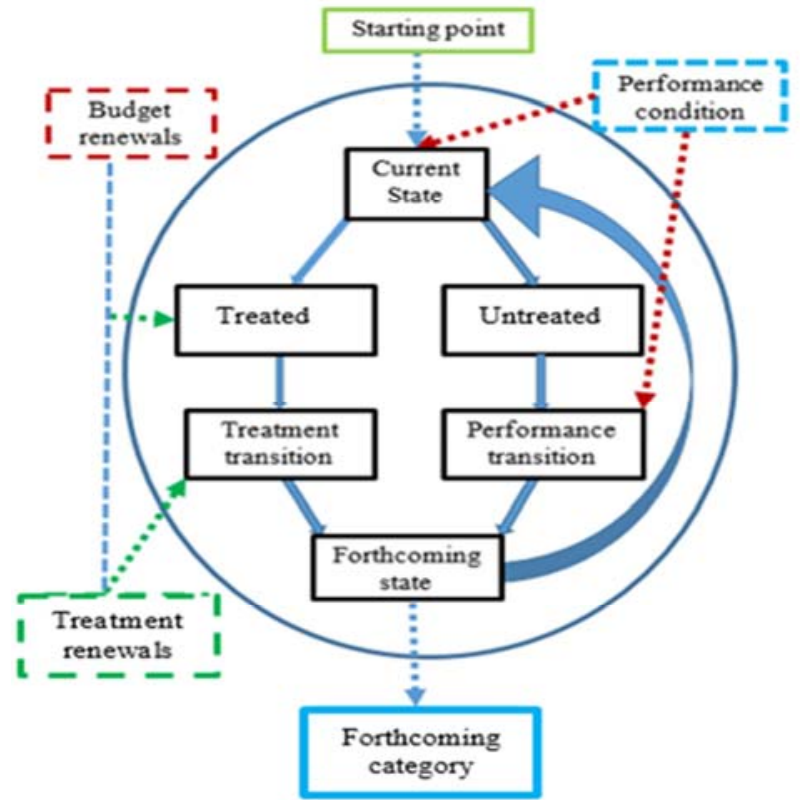

Fig. 5. Strategic model for asset deterioration transition and decision

Table IV

Attributes definition for strategic model

\begin{tabular}{|l|l|}
\hline i & $\begin{array}{l}\text { Current state: The state of which the asset represents before modeled for a } \\
\text { forthcoming state } \\
\text { ii }\end{array}$ \\
iii & $\begin{array}{l}\text { Perfoated quantity: The portion of an asset having no treatment intervention } \\
\text { Forthcoming state: } \text { The projected state from the current state of treated or untreated } \\
\text { quantity }\end{array}$ \\
v & $\begin{array}{l}\text { Performance condition: The forthcoming condition of the current state having no } \\
\text { treatment }\end{array}$ \\
vi & $\begin{array}{l}\text { Budget renewals: The annual budgeted figure needed for each of the treatment } \\
\text { Treated quantity: The portion of an asset that treatment intervention was conducted } \\
\text { vii } \\
\text { viii }\end{array}$ \\
ix & $\begin{array}{l}\text { Treatment transition: The transition probability matrix in an improvement context } \\
\text { Treatment action }\end{array}$ \\
$\mathrm{x}$ & $\begin{array}{l}\text { Forthcoming state: } \text { The projected state from the current state of treated or untreated } \\
\text { quantity } \\
\text { Forthcoming category: } \\
\text { untreated quantity }\end{array}$ \\
$\mathrm{xi}$
\end{tabular}


The estimation for CS is imperative as it represents the definition of the asset condition used in describing the condition bands. In the revolvement towards the FS from the starting point, transition probability from two consecutive inspection periods having no maintenance (untreated) or maintenance (treated) intervention is essential to obtain the respective performance transition or treatment transition [14]. These helps in determining the performance condition and treatment renewal knowledge required for an optimized decision making of when the best to carry out maintenance activity.

\section{Application to carriageway}

The results from the application of the proposed models are used to develop appropriate maintenance program for carriageway in order to ensure continuous functionality and availability. The proposed method is applied and evaluated using condition improvement between the two successive inspections from the Surface Condition Assessment of National Network of Roads (SCANNER) survey of the United Kingdom Pavement Management System. SCANNER surveys are used for the collection of data for carriageway surface condition. It is developed on behalf of the Department for Transport (DfT) to provide an accurate, consistent approach for assessing the condition of all principal roads across the United Kingdom.

The result depicts the change that occurs at different condition states of the carriageway. The deterioration profile is illustrating the 20 years spread between the various condition states. The deterioration levels after every five years are presented in Fig. 6.

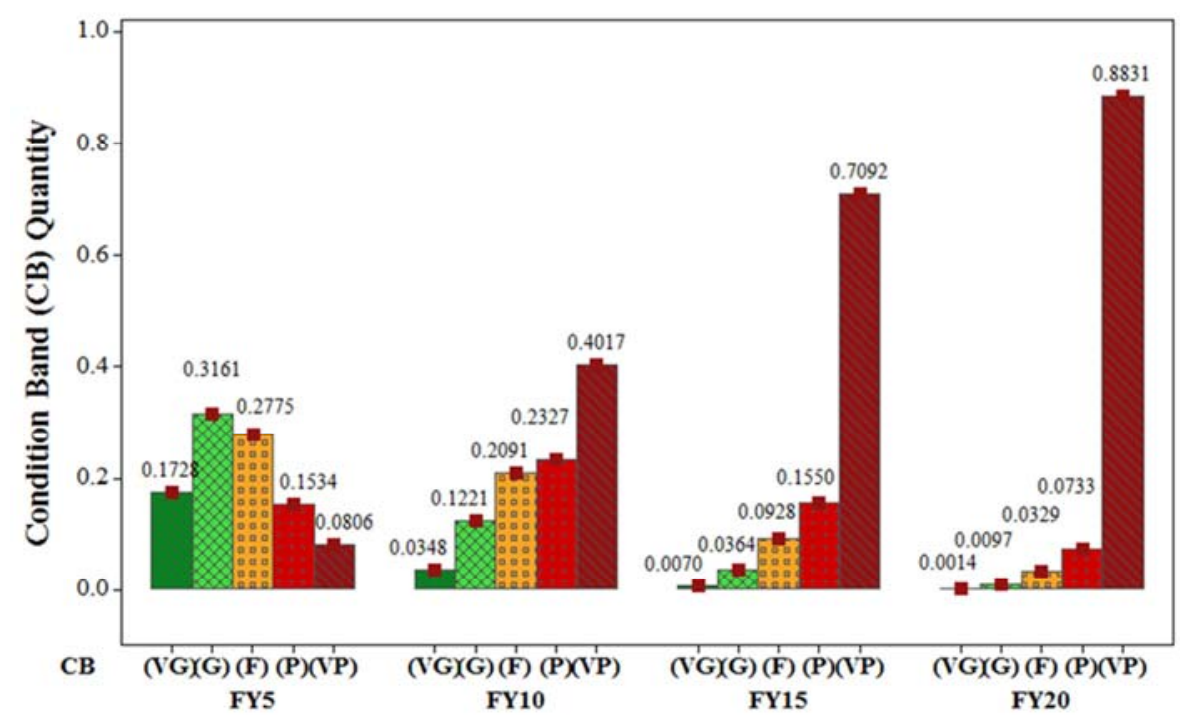

Fig. 6. Predicted future year (FY) deterioration for 5, 10, 15 and 20 years 
The predicted condition state could assist asset managers to understand the possible deteriorations of the carriageway and help to identify the best time to carry out maintenance actions. Asset owners look forward to ensuring that the carriageway is above the fair level. This will enable them to avoid reactive maintenance and provide more preventive and condition based maintenance. The Markov chain model still happens to be one of the most appropriate tools for predicting the future condition of physical assets.

\section{Conclusion}

The research aims to propose methodologies of a reliability based asset management for highway infrastructures. The methods presented in the paper enable highway asset owners, and managers to develop reliability based maintenance strategies and to maintain newly created and already existing fielded highway infrastructures. In the maintenance of fielded highway assets, multiple maintenance methodologies are to be taking into applications. This quad process would help to ensure that the maintenance of the various aspects of the asset lifecycle is well-thought-out. The quad approaches developed for the asset maintenance in this paper are in themselves valuable means for asset owners and maintenance managers. The methods are useful in determining appropriate maintenance type and time, thereby creating an excellent platform for decision making. The methodology and processes developed in the paper have the capability to support organization in enhancing their well-established maintenance programs. The methods are organized to follow the generalized principle of reliability based maintenance and should allow asset managers to implement them impeccably in conjunction with their existing processes.

\section{Acknowledgements}

This work has been undertaking on as a part of a project funded by the Niger Delta Development Commission (NDDC), Port Harcourt, River State, Nigeria and the Delta State Government Scholarship and Bursary (DTSG), Asaba, Delta State, Nigeria.

\section{References}

[1] County Surveyors Society, Framework for highway asset management, City Surv Soc, London, The Stationary Office, 2004.

[2] UK Bridges Board, Management of highway structures, A code of practice, London, The Stationary Office, 2005.

[3] Frangopol D. M., Mohamed S. Life-cycle of structural systems: Recent achievements and future directions, Structure and Infrastructure Engineering, Vol. 12, No. 1, 2016, pp. 1-20.

[4] UK Roads Board, Well- maintained highways, Code of practice for highway maintenance management, London, The Stationary Office (TSO), 2005.

[5] Economic Development Research Group, Failure to act, The impact of current infrastructure investment on America's economic future, Virginia, 2013. 
[6] Department for Transport, Highways Agency, 2010 to 2015 government policy, road network and traffic, 2015, https://www.gov.uk/government/publications/2010-to-2015government-policy-road-network-and-traffic (last visited 25 July 2015).

[7] Ekpiwhre E. O., Tee K. F. Reliability-centered maintenance of road junction transport assets, In: Kruis J, Tsompanakis Y, Topping B. H. V. (Eds) Proc. of Fifteenth Int. Conf. Civil, Struct. Environ. Eng. Comput. Prague, Czech Republic, 1-4 September 2015, CivilComp Press, 2015, Paper 279.

[8] Mariut L., Helerea E., Felea I. Underground power cables-life analysis and reliability prognosis, Pollack Periodica, Vol. 7, No. 3, 2012, pp. 3-14.

[9] Ekpiwhre E. O., Tee K. F. Reliability based maintenance for sustainable transport asset management, In: Iványi P., Bachmann B. Kvasznicza Z. (Eds.) 12th Miklós Iványi Int. PhD DLA Symp, Pollack Press, Pécs, Hungary, 3-4 November 2016, p. 38.

[10] Ekpiwhre E. O., Tee K. F., Aghagba S., Bishop K. Risk-based inspection on highway assets with category 2 defects, Int J Safety Security Eng, Vol. 6, No. 2, 2016, pp. 372-382.

[11] Washer G., Connor R., Nasrollahi M., Reising R. Verification of the framework for riskbased bridge inspection, Journal of Bridge Engineering, Vol. 21, No. 4, 2016, paper 04015078 .

[12] Ekpiwhre E. O., Tee K. F., Mordi O., Bull T. Carriageway deterioration prognosis modelling using Markovian chain, In: Scarf P., Wu S., Do P. (Eds) Proc.of 9th IMA Int. Conf. Model. Ind. Maint. Reliab, London, UK, 12-14 July 2016, pp. 58-63.

[13] Wellalage N. K. W., Zhang T., Dwight R. Calibrating Markov chain-based deterioration models for predicting future conditions of railway bridge elements, Journal of Bridge Engineering, Vol. 20, No. 2, 2015, paper 04014060.

[14] Ekpiwhre E. O., Tee K. F. Cost modelling of carriageway treatment transition for strategic maintenance optimisation, In: Institute of Asset Management, Institute of Engineering \& Technology, (Ed.) Profs. of Asset Manag. Conf, London, UK, 23-24 November 2016, paper 7.a.2.

[15] Kota L., Jarmai K. Efficient algorithms for optimization of objects and systems, Pollack Periodica, Vol. 9, No. 1, 2014, pp. 121-132.

[16] Khan L. R., Tee K. F. Risk-cost optimization of buried pipelines using subset simulation, Journal of Infrastructure Systems, ASCE, Vol. 22, No. 2, 2016, 04016001.

[17] Orugbo E. E, Alkali B., DeSilva A., Harrison D. K. RCM and AHP hybrid model for road network maintenance prioritization, Baltic Journal of Road \& Bridge Engineering, Vol. 10, No. 2, 2015, pp. 182-190.

[18] US Navy Sea Systems, Reliability-centered maintenance (RCM) handbook, vol. S9081AB-G. U.S Navy Sea Systems Command, 2007.

[19] Ascher H, Feingold H. Repairable systems reliability, modeling, inference, misconceptions and their causes, NY, M Dekker 1984.

[20] Crow L. H. Reliability analysis for complex, repairable systems, technical report No. 10, US Army Materials Alaysis Activity, 1975.

[21] Duane J. T. Learning curve approach to reliability monitoring, IEEE Trans Aerosp, Vol. 2 , No. 2, 1964, pp. 563-566.

[22] Transport for London good practice guide, Risk based inspection for highway structures, Attkins, London, 2011.

[23] Fang Y., Xiong J., Tee K. F. Time-variant structural fuzzy reliability analysis under stochastic loads applied several times, Structural Engineering and Mechanics, Vol. 55, No. 3, 2015, pp. 525-534. 
[24] Khemis A., Hacene-Chaouche A., Athmani A., Tee K. F. Uncertainty effects of soil and structural properties on the buckling of flexible pipes shallowly buried in Winkler foundation, Structural Engineering and Mechanics, Vol. 59, No. 4, 2016, pp. 739-759.

[25] Zhang Y., Kim C. W., Tee K. F. Maintenance management of offshore structures using Markov process model with random transition probabilities, Structure and Infrastructure Engineering, Vol. 13, No. 8, 2017, pp. 1068-1080.

[26] Fang Y., Tao W., Tee K. F. Time-domain multi-state markov model for engine system reliability analysis, Mechanical Engineering Journal, Vol. 3, No. 3, 2016, paper 16-00084. 